\title{
AS ESCRITAS DE SI E OS EFEITOS MOBILIZADORES DA FORMAÇÃO DOCENTE EM NARRATIVAS (AUTO)BIOGRÁFICAS
}

\author{
Joelson de Sousa Morais ${ }^{1}$, Franc-Lane Sousa Carvalho do Nascimento ${ }^{2}$, Maria Divina Ferreira Lima ${ }^{3}$
}

${ }^{1}$ Doutorando em Educação pela Universidade Estadual de Campinas - UNICAMP (Bolsista CAPES). É pesquisador do Grupo de Estudos e Pesquisas em Educação Continuada - GEPEC/UNICAMP, do Grupo Interinstitucional de Pesquisaformação Polifonia - UNICAMP/UERJ, do Grupo de Pesquisas Interdisciplinares: Educação, Saúde e Sociedade - UEMA/CPNQ e do Núcleo de Pesquisa em Educação, Formação Docente, Ensino e Práticas Educativas NUPEFORDEPE/UFPI. ORCID iD: http://orcid.org/0000-0003-1893-1316. E-mail: joelsonmorais@hotmail.com

${ }^{2}$ Doutora em Educação pela Universidade Federal do Rio Grande do Norte - UFRN. Líder do Grupo de Pesquisas Interdisciplinares: Educação, Saúde e Sociedade - CNPq/UEMA. Professora do Departamento de Educação da Universidade Estadual do Maranhão - UEMA, Centro de Estudos Superiores de Caxias - CESC, e atualmente Diretora do Curso de Pedagogia. Professora permanente do Programa de Pós-Graduação em Educação (PPGE) - Mestrado Profissional em Educação da UEMA. Trabalha ainda como Coordenadora Pedagógica e Formadora na Secretaria Municipal de Educação, Ciências e Tecnologia de Caxias (MA) - SEMECT. ORCID iD: http://orcid.org/0000-0001-69564670. E-mail: franclanecarvalhon@gmail.com

${ }^{3}$ Doutora em Educação pela Universidade Federal do Rio Grande do Norte - UFRN. É Professora do Departamento de Métodos e Técnicas de Ensino - DMTE e Docente Permanente do Programa de Pós-Graduação em Educação da Universidade Federal do Piauí - UFPI - PPGED/UFPI. Coordenadora do Núcleo de Pesquisa em Educação, Formação Docente, Ensino e Práticas Educativas - NUPEFORDEPE. ORCID iD: http://orcid.org/0000-0002-4552-6802. E-mail: lima.divina2@gmail.com

\section{RESUMO}

Este texto se configura como uma pesquisa teórica-bibliográfica primando pela abordagem narrativa (auto)biográfica para pensarmos os processos de formação de professores a partir das escritas de si enquanto contribuidoras de construção de saberes, conhecimentos e transformações que esta pode propiciar. Nos propomos a questionar como problemática de pesquisa: Quais as contribuições das escritas de si nos processos de formação de professores tecidas em narrativas (auto)biográficas? Diante do exposto tecemos como objetivos deste artigo: entender os aspectos históricos-epistemológicos do campo das narrativas (auto)biográficas no Brasil; compreender o movimento da formação profissional da docência mediada pelas escritas narrativas de si, bem como refletir acerca das contribuições das narrativas (auto)biográficas escritas no processo de formação e desenvolvimento profissional de professores. A fundamentação teórico-epistemológica deste texto se pauta nos princípios da abordagem narrativa (auto)biográfica a qual somos pesquisadores dessa área. Os resultados do estudo revelam que o desafio posto no processo de formação de professores no contexto de uma pedagogia narrativa, é a adoção de dispositivos metodológicos na prática pedagógica pelos formadores de professores, com o uso de escritas narrativas de si, que pode ser empreendida pelo próprio formador, em diálogo com os estudantes em formação, para que criem uma cultura da escrita, e possam contribuir no seu processo formativo construindo conhecimentos e saberes necessários à profissão que os acompanharão, inclusive, no desenvolvimento profissional docente quando estiverem atuando na área.

Palavras-chave: Escritas de si. Narrativas (auto)biográficas. Formação de Professores.

\section{SELF WRITING AND THE MOBILIZING EFFECTS OF TEACHING TRAINING IN (AUTO) BIOGRAPHIC NARRATIVES}

\section{ABSTRACT}

This text is configured as a theoretical-bibliographic research, emphasizing the narrative (auto) biographical approach to think about the processes of teacher training based on the writings of themselves as contributing to the construction of knowledge, knowledge and transformations that this can provide. We 
propose to question as a research problem: What are the contributions of the writings of oneself in the teacher education processes woven into (auto) biographical narratives? In view of the above, we weave as objectives of this article: to understand the historical-epistemological aspects of the field of (auto) biographical narratives in Brazil; understand the movement of professional teaching training mediated by the narrative writings of themselves, as well as reflect on the contributions of the (self) biographical narratives written in the process of teacher training and professional development. The theoreticalepistemological foundation of this text is based on the principles of the narrative (auto) biographical approach to which we are researchers in this area. The results of the study reveal that the challenge posed in the process of teacher training in the context of a narrative pedagogy, is the adoption of methodological devices in pedagogical practice by teacher trainers, with the use of narrative writings of themselves, which can be undertaken by the trainer himself, in dialogue with students in training, so that they create a culture of writing, and can contribute to their formative process by building knowledge and knowledge necessary for the profession that will accompany them, including, in the professional development of teachers when they are working in the area.

Keywords: Self-written. (Auto) biographical narratives. Teacher training.

\section{LA AUTOESCRITURA Y LOS EFECTOS MOVILIZADORES DE LA ENSEÑANZA DE LA FORMACIÓN EN NARRATIVAS (AUTO) BIOGRÁFICAS}

\section{RESUMEN}

Este texto se configura como una investigación teórico-bibliográfica, enfatizando el enfoque narrativo (auto) biográfico para pensar en los procesos de formación docente a partir de los escritos de ellos mismos como contribuyentes a la construcción de saberes, saberes y transformaciones que puede brindar. Proponemos cuestionar como problema de investigación: ¿Cuáles son las aportaciones de los escritos de uno mismo en los procesos de formación docente entretejidos en narrativas (auto) biográficas? En vista de lo anterior, tejemos como objetivos de este artículo: comprender los aspectos histórico-epistemológicos del campo de las narrativas (auto) biográficas en Brasil; comprender el movimiento de la formación profesional docente mediado por los escritos narrativos de sí mismos, así como reflexionar sobre los aportes de las narrativas (auto) biográficas escritas en el proceso de formación y desarrollo profesional docente. El fundamento teórico-epistemológico de este texto se basa en los principios del enfoque narrativo (auto) biográfico del que somos investigadores en esta área. Los resultados del estudio revelan que el desafío que se plantea en el proceso de formación docente en el contexto de una pedagogía narrativa, es la adopción de dispositivos metodológicos en la práctica pedagógica por parte de formadores de docentes, con el uso de escritos narrativos sobre sí mismos, que pueden ser realizados por el propio formador, en diálogo con los estudiantes en formación, para que creen una cultura de la escritura y puedan contribuir a su proceso formativo mediante la construcción de conocimientos y conocimientos necesarios para la formación. profesión que los acompañará, incluso, en el desarrollo profesional de los docentes cuando se encuentren trabajando en el área.

Palabras clave: Autoescrito. Narrativas (auto) biográficas.

\section{INTRODUÇÃO}

Este texto se configura como uma pesquisa teórica-bibliográfica que alude aos processos de formação profissional da docência fundamentando-se na abordagem narrativa (auto)biográfica para pensarmos os vários níveis de composição das escritas enquanto efeitos mobilizadores de reflexões, aprendizagens e transformações tecidas no contexto da formação de professores.
Escrever sobre si em tempos cada vez mais aligeirados como esse em que vivemos no século XXI, tão fortemente tomado por atividades rotineiras, caracterizado por bruscas transformações nas relações políticas, econômicas, culturais, sociais e educacionais, nos traz um alento e ao mesmo tempo uma forma de combater a trivialidade e outros tantos modos de não passarmos despercebidos de uma história que pode ser produzida potencialmente em registros cotidianos de narrativas que falam 
muito de nós, mas também de nossa profissão, das pessoas com as quais convivemos, da formação que estamos tecendo e outros tantos atravessamentos e contextos que emergem em nossa vida, em nossa história.

Essa temporalização cada vez mais frenética e rápida das atividades que realizamos, seja em nossa vida, no contexto da formação de professores e no desenvolvimento profissional, acaba, portanto, deixando pouco espaço para a atividade de narrar e refletir sobre o que estamos produzindo, o que isso se demonstra pelo que Benjamin (2012, p.213), critica de que "[...] é a experiência de que a arte de narrar está em vias de extinção. São cada vez mais raras as pessoas que sabem narrar devidamente".

Por isso, buscamos lutar contra as formas com que as informações se alastram de modo muito acelerado nessa modernidade avançada, construindo, portanto, conhecimentos por meio das escritas narrativas de si, em que tanto nós professores formadores tecemos em nossos registros, como o que produzem os nossos estudantes dos cursos de formação de professores os quais temos atuado e privilegiado as escritas de si, como dispositivo de acompanhamento, avaliação, formação e aprendizagem, acreditando que esse exercitar a escrita narrativa, pode acompanhar os sujeitos em diferentes momentos de sua existência, ampliando os horizontes de compreensão de si, do mundo à sua volta e do que faz, entre outros aspectos.

Portanto, a nossa pretensão que temos nesse texto é trazermos outras tantas reflexões que deem centralidade às narrativas (auto)biográficas como modo de dar sentido às histórias de vida dos sujeitos, podendo contribuir para as transformações de si, e a constituição de meios que personalizam os processos formativos em diferentes espaços e temporalidades pela via da narração, afinal de contas, "[...] usamos histórias para dar sentido à nossa experiência e para construir significado e propósito para nossas vidas" (GOODSON, 2019, p. 109).

Há muitos dispositivos pelos quais o sujeito pode produzir e registrar narrativamente as escritas de si, e que representam meios privilegiados de contar histórias, com diferentes finalidades, propósitos e intensidades. No processo de formação de professores, temos utilizado como artefatos de escritas de si com os nossos estudantes: diários, memorial de formação, cartas, portfólios, narrativas do estágio supervisionado ${ }^{1}$, entre outros meios.

A ideia desse texto é fazer uma incursão reflexiva no campo da abordagem narrativa (auto)biográfica em educação, com foco nos processos formativos da docência em que estamos inseridos como professores pesquisadores e formadores nos cursos de licenciaturas em diferentes contextos em que atuamos na docência do Ensino Superior, ao mesmo tempo articulando-se com nossas múltiplas outras experiências tecidas no âmbito da formação de professores.

Por isso, como professores/pedagogos que somos, acreditamos nos efeitos pedagógicos, formativos e emancipatórios que a escrita narrativa é capaz de produzir tanto na formação do sujeito, como na tomada de consciência dos percursos trilhados, podendo contribuir não somente nesse contexto, mas intercambiar-se por outras múltiplas experiências que poderá se envolver em situações diversas, e momentos diferentes da vida, formação e desenvolvimento profissional do professor.

A provocação refletiva enquanto questão disparadora de problema de pesquisa neste texto nos impulsiona a buscar saber: Quais as contribuições das escritas de si nos processos de formação de professores tecidas em narrativas (auto)biográficas? Como professores formadores e pesquisadores que somos compreendemos que tanto a dimensão social quanto a individual do sujeito ajudam no processo de constituição de uma memória sólida e formativa, bem como na tessitura da reflexão mediada pela escrita narrativa, e que as instituições educativas e formativas, neste caso as universidades também se tornam importantes na organização e produção da memória/narração, ajudando na formação e no desenvolvimento profissional docente.

Pensamos como objetivos deste artigo: entender os aspectos históricos-epistemológicos do campo das narrativas (auto)biográficas no Brasil; compreender o movimento da formação profissional da docência mediada pelas escritas narrativas de si, bem como refletir acerca das

\footnotetext{
1 No lugar da produção de um relatório que é entregue pelo estudante do Ensino Superior, no final da disciplina em que estamos ministrando de Estágio Supervisionado, priorizamos uma escrita narrativa (auto)biográfica, a fim de romper com um modo de escrita meramente descritiva. Damos centralidade aos aspectos subjetivos, pessoais e das implicações e afetações geradas no sujeito que possam ser suscitadas no contexto do estágio que se materializam suas experiências por meio das narrativas (auto)biográficas.
} 
contribuições das narrativas (auto)biográficas escritas no processo de formação e desenvolvimento profissional de professores. Desta forma, neste estudo abordamos a importância de trabalharmos as narrativas com estudantes nos cursos de formação de professores, para que tenham maior autonomia intelectual e possam atuar profissionalmente de forma reflexiva no seu cotidiano, motivando seus futuros alunos para que sejam sujeitos protagonistas também de seus próprios aprendizados.

Este texto se compõe de quatro partes, entre as quais esta se configura como a primeira trazendo algumas reflexões iniciais do estudo; enquanto que a segunda parte, traz alguns marcos históricos das narrativas (auto)biográficas no Brasil no contexto da educação; já na terceira parte enfocamos a pertinência das escritas de si na formação docente; e na quarta e última seção trazemos algumas reflexões conclusivas a que a pesquisa nos trouxe.

\section{AS NARRATIVAS (AUTO)BIOGRÁFICAS EM UMA PERSPECTIVA HISTÓRICA-EPISTEMOLÓGICA: CONTRIBUTOS E POTENCIALIDADES}

Refletimos nesse componente do texto algumas contribuições que as narrativas (auto)biográficas podem trazer no processo de formação de professores. Para isso, fazemos um duplo movimento: o de pensar as escritas de si no contexto da formação inicial docente, e suas articulações em relação ao desenvolvimento profissional de professores no cotidiano da escola pública fundamental, espaços/tempos esses em que tanto estamos imersos como formadores de professores, como enquanto pesquisadores em que estes sujeitos compartilham conosco a produção, reflexão e acesso às suas narrativas nos processos de aprendizagem e formação que estas possibilitam em suas/nossas vidas.

Alguns contundentes estudos desenvolvidos por Passeggi e Souza (2017) e Bragança (2018) evidenciam de uma forma mais adensada e completa as relevantes contribuições que historicamente têm sido trazidas pelo movimento (auto)biográfico no Brasil, com o qual nos fundamentamos neste texto, em articulação com outros autores.

Embora tenham existido outros acontecimentos e marcos que puderam se caracterizar como uma emergência e mesmo se configurado como origem das narrativas (auto)biográficas tanto no cenário brasileiro como internacional, optamos por retratar alguns focos, considerando o que acreditamos ser de uma pertinência para as pesquisas no campo da formação de professores e da abordagem narrativa como perspectiva teóricaepistemológica a ser elucidada.

Nesse sentido, a princípio, apresentamos um recorte cronológico pautando-nos a partir de três profundos e determinantes acontecimentos de grande relevância para o campo da educação e da formação de professores nesse contexto, quais sejam: 1) o movimento operado no Brasil entre as décadas de 1960 e 1970 com o que consideramos $\mathrm{o}$ desenvolvimento de uma pedagogia narrativa que iremos explicitar a seguir; 2) o surgimento das histórias de vida na formação de adultos com a pesquisa-formação nos inícios da década de 1980 com as contribuições de alguns autores da Europa, Canadá e francófonos no cenário europeu dando legitimidade a estudos e pesquisas acadêmicas voltando-se a essa perspectiva; e, 3) a emergência do campo das narrativas com um maior desenvolvimento e propriedade novamente no Brasil na década de 1990, recolocando o papel da formação de professores e o desenvolvimento profissional docente, passando para a sua ampliação e diversificação nos anos 2000 e que nos acompanha até os dias atuais.

Primeiramente, ressaltamos que "[...] a utilização das abordagens (auto)biográficas é fruto da insatisfação das ciências sociais em relação ao tipo de saber produzido e da necessidade de uma renovação dos modos de conhecimento científico" (NÓVOA, 1992, p. 18).

Quanto ao primeiro ponto, a citar: o movimento operado no Brasil entre as décadas de 1960 e 1970 com o que consideramos o desenvolvimento de uma pedagogia narrativa, ressaltamos que as narrativas (auto)biográficas no cenário brasileiro foram inicializadas primeiramente com os contributos de um proeminente educador brasileiro pernambucano que trouxe um legado inestimável para a criação de políticas públicas educacionais, os processos de alfabetização e as práticas emancipatórias fundamentais para o desenvolvimento do povo brasileiro, com ênfase para o campo educacional que nos acompanha na sociedade contemporânea, que foi o insigne Paulo Freire através da tendência pedagógica Pedagogia Libertadora. 
A esse respeito, reforçamos os estudos da abordagem narrativa que retrata esse marco fundante dessa perspectiva, que embora na época não tinha a denominação de narrativa (auto)biográfica, o autor já produzia um modo de narrar a experiência em movimentos instituintes e reflexivos no campo da formação humana, e, sobretudo, no concernente à formação de professores. Assim, assevera Bragança (2018) que vem discorrendo acerca desse marco em seus escritos acerca do educador brasileiro:

No Brasil, podemos tomar a vida e obra de Paulo Freire como marco na direção de práticas educativas que consideram a trajetória de vida os educandos, especialmente jovens e adultos, suas histórias, saberes e narrativas como referências para a construção de conhecimentos em uma educação especialmente dialógica. Em sua obra como professorpesquisador, encontramos uma escrita reflexiva sobre a própria prática e narrativas autobiográficas que partilham as itinerâncias que o levaram à docência. Seu trabalho fertiliza, em meio a resistências políticas e epistemológicas, práticas emancipatórias que colocam foco na vida de educandos e educadores, como sujeitos individuais e coletivos (BRAGANÇA, 2018, p. 72).

Foi com os contributos de um modo outro de escrita narrativa que pontuavam os movimentos subjetivos de se colocar frente à sociedade de sua época e, sobretudo, da educação, que Paulo Freire conseguiu alcançar mudanças substanciais no perfil de homem, educação e políticas educacionais que chegamos a conquistar historicamente no Brasil. Além do mais, sua obra, trouxe uma exponencial aceitação e circulação no campo da educação no Brasil e internacionalmente, se tornando um contributo para fundamentar a realização de outras tantas pesquisas, estudos e temáticas com relevância nos modos de escrita narrativa (auto)biográfica, que acreditamos que educadores e pesquisadores passaram a adotar essas perspectivas com inúmeras influências deste educador brasileiro.

Embora existam outros tantos escritos de Paulo Freire, bem anterior a esse que vamos apresentar a seguir, não podemos deixar de mencionar o modo como escrevia narrativamente $\mathrm{o}$ autor, trazendo suas experiências de mundo, e ao mesmo tempo as compreensões de si, à sua volta, da sociedade, da política, da educação e outros tantos modos de expor narrativamente no plano da escrita formas de lutas que ganhavam contornos de visibilidade quando lidos por muitos professores, educadores brasileiros e outros profissionais de diferentes áreas do conhecimento. Freire (1996), em Pedagogia da autonomia, pontua em um dos saberes necessários à prática educativa, o seguinte:

[...] O que devo pretender
não é a neutralidade da
educação, mas o respeito,
a toda prova, aos
educandos, aos
educadores e às
educadoras. o respeito
aos educadores e
educadoras por parte da
administração pública ou
privada das escolas; o
respeito aos educandos
assumido e praticado
pelos educadores não
importa de que escola,
particular ou pública. É por
isto que devo lutar sem
cansaço. Lutar pelo direito
que tenho de ser
respeitado e pelo dever
que tenho de reagir a que
me destratem. Lutar pelo
direito que você, que me
lê, professora ou aluna,
tem de ter você mesma e
nunca, jamais, lutar por
essa coisa impossivel,
acinzentada e insossa que
é a neutralidade (FREIRE,
1996, p. 111-112).

Observamos com essa escrita narrativa, tanto quanto várias outras produzidas por Paulo Freire e publicadas em várias de suas obras, foi caracterizando-se como um modo de romper 
com os modelos clássicos de escrita de sua própria época, fazendo emergir outros saberes, conhecimentos e experiências que na escrita narrativa (auto)biográfica se potencializava e provocava reflexões, entendimentos e formação aos leitores, professores e pesquisadores, em sua maioria.

Assim, pensamos que esse escritor e educador brasileiro, acabou rompendo com uma lógica hegemônica de produção do conhecimento científico dando abertura a outras possibilidades que pudessem ser descortinadas no campo da ciência e da própria ideia de produzir conhecimento, nesse caso narrativamente.

Refletimos ainda, que, a escrita de Paulo Freire mesmo que tenha sido produzida pelo viés de uma escrita narrativa (auto)biográfica, ela não era assim mencionada e designada na época, mas que depois, passamos a pensar na potencialidade dessa forma de escrita, inclusive, fundamentando inúmeras pesquisas narrativas no campo da educação e da formação de professores no Brasil, como até hoje se revela profícua nos apropriar de sua obra e pensar a escrita reflexiva narrativa.

$O$ segundo ponto importante que queremos elucidar ainda no contexto do Brasil, trata-se da proposta idealizada pela escrita narrativa de um memorial de formação na década de 1980, pela professora Magda Becker Soares apresentada na Universidade Federal de Minas Gerais (UFMG) como requisito para professora titular desta instituição, em que apresenta um modo de escrever que dá centralidade ao universo pessoal, como formativo, profissional e de outros contextos que elucida em sua escrita narrativa (auto)biográfica, configurando-se como um ressurgimento deste gênero no âmbito das universidades no cenário brasileiro (CÂMARA; PASSEGGI; 2013).

O memorial (auto)biográfico, portanto, foi emergindo no campo da educação e da formação de professores como um potencial dispositivo de aprendizagem e de uma escrita de $\mathrm{si}$, que se tornou referência para inúmeros estudos e produções de conhecimentos científicos no âmbito brasileiro.

De acordo com Abrahão (2016), no cenário internacional, podemos citar os pioneiros das histórias de vida em formação com as contribuições de Gaston Pineau na Universidade de Montreal (Canadá), em que na mesma época no início da década de 1980, também foram propostos os processos de formação de adultos com o uso da escrita narrativa (auto)biográfica também com o trabalho desenvolvido por Marie Christine Josso, Gaston Pineau e Mattias Finger na Universidade de Genebra (Suíça) com a pesquisa-formação como perspectiva teóricometodológica e epistemológica no campo da formação de professores e como aspecto crucial no desenvolvimento de aprendizagens e transformações que pudessem gerar por esse modo de escrita subjetiva em relação aos aspectos emancipatórios dessa formação na vida, experiência e desenvolvimento profissional destes.

As práticas de formação desenvolvidas por uma escrita narrativa (auto)biográfica de professores, a partir dos ideais disseminados pelos autores mencionados se tornaram uma dimensão importante no desenvolvimento de estudos e pesquisas que se espalharam por várias partes do mundo, inclusive, chegando com muito apreço e empatia no Brasil. Trata-se de uma escrita como um voltar para si, e perceber as nuances, múltiplos afetamentos e transformações que as escritas de si podem recuperar e contribuir na própria formação e (auto)formação do sujeito, produzindo transformações e processos emancipatórios.

$$
\text { o surgimento dos estudos }
$$

(auto)biográficos no Brasil foram decorrentes das influências de estudos e pesquisas dos referidos autores mencionados acima, do âmbito das correntes das histórias de vida em formação que segundo Passeggi; Souza (2017, p.13) declaram que "[...] o momento inaugural em Educação, acontece nos anos 1990, com os trabalhos e pesquisas desenvolvidas pelo Grupo de Estudos Docência, Memória e Gênero (GEDOMGE), criado em 1994, na Faculdade de Educação da Universidade de São Paulo (FEUSP)". Com esse grupo, é possível perceber que "[...] essa é a primeira filiação do movimento (auto)biográfico em Educação, no Brasil".

Buscando elucidar o terceiro ponto que apresentamos no início desta seção, reiteramos o marco da recolocação do protagonismo dos professores com o uso das histórias de vida e narrativas (auto)biográficas a partir do que Nóvoa (1992) chama de "viragem epistemológica", no sentido de fazer com que os professores e seus processos de formação sejam considerados e visibilizados, o que de certo modo não vinha acontecendo a contento, e daí, o surgimento de pesquisas e estudos que pudessem situar não somente os aspectos políticos e institucionais da formação e profissão docente, mas sobretudo dar 
centralidade a vida do professor, o que foi reforçado com a indissociabilidade entre o ser pessoa e profissional como defende o próprio autor, e que tem sido de uma profunda relevância nas pesquisas e na ressignificação da formação e do trabalho docente, a partir de então.

Avançando, podemos citar o ressurgimento das narrativas (auto)biográficas no Brasil no campo da educação, com ênfase no processo de formação de professores, com o surgimento do livro $O$ método (auto)biográfico $e$ a formação ${ }^{2}$, por volta da década de 1990, com organização de António Nóvoa e Matthias Finger, e que teve ampla circulação e uso nas pesquisas e nas produções de conhecimentos científicos no cenário brasileiro, servindo de referência para o campo das narrativas e da formação de professores.

Mais recentemente, no ano de 2004 tivemos a criação do Congresso Internacional de Pesquisa (Auto)Biográfica (CIPA) ${ }^{3}$, que teve sua primeira edição realizado em Porto Alegre (I (IPA), e que é um evento que é promovido bianualmente em diferentes regiões do Brasil (atualmente já se encontra em sua IX edição) e congrega pesquisadores de vários lugares tanto do cenário nacional, quanto internacional, tematizando as histórias de vida, as narrativas (auto)biográficas e a pesquisa-formação com produções que se revelam nessas perspectivas, se tornando uma referência para os estudiosos da área, produção do conhecimento e socialização de estudos e pesquisas nesta abordagem. Portanto, o CIPA tem se configurado como um importante evento de discussões e reflexões na

\footnotetext{
${ }^{2}$ Uma mais recente edição deste livro foi publicada no ano de 2010 pela editora da Universidade Federal do Rio Grande do Norte (UFRN) EDUFRN em parceria com a editora Paulus no contexto da Coleção Pesquisa (Auto)biográfica - Educação - Clássicos das histórias de vida, sob coordenação da profa. Maria da Conceição Passeggi, Elizeu Clementino de Souza e Christine Delory-Momberger (ver NÓVOA; FINGER, 2010).

${ }^{3}$ Cabe destacarmos quando e onde aconteceram esses eventos, a saber: o primeiro evento que foi o I CIPA foi realizado em 2004, em Porto Alegre, na Pontifícia Universidade Católica do Rio Grande do Sul (PUCRS); o II CIPA aconteceu em 2006 em Salvador na Universidade Estadual da Bahia (UNEB); o III CIPA foi promovido pela Universidade Federal do Rio Grande do Norte (UFRN) em Natal no ano de 2008; o IV CIPA foi realizado na Universidade de São Paulo (USP) em São Paulo no ano de 2010; o V CIPA aconteceu em Porto Alegre em 2012 na PUCRS; em 2014 foi realizado o VI CIPA no Rio de Janeiro na Universidade do Estado do Rio de Janeiro (UERJ); enquanto que o VII CIPA foi realizado em Cuiabá, na Universidade Federal do Mato Grosso (UFMT); o VIII CIPA foi promovido em São Paulo na Universidade Cidade de São Paulo (UNICID), e o próximo evento o IX CIPA está previsto para acontecer no final do primeiro semestre de 2021 na Universidade de Brasília (UNB).
}

área da abordagem da Pesquisa Narrativa (Auto)Biográfica.

Como uma importante fonte de produção de saberes, conhecimentos e experiências, a realização dos CIPA's, vem originando a publicação tanto dos trabalhos científicos que são apresentados nos eventos no campo da abordagem narrativa (auto)biográfica tematizando, entre outras coisas, as relativas à formação de professores, memórias, experiências e o desenvolvimento profissional docente, além de livros que vem ampliando-se, exponencialmente esse campo do conhecimento atraindo outros tantos professores pesquisadores.

No VIII CIPA, por exemplo, que foi o último evento realizado na UNICID (em São Paulo) se consolidou na publicação de sete volumes da coleção Pesquisa (auto)biográfica, mobilidades, incertezas e refigurações identitárias, a saber: Pesquisa (auto)biográfica: diálogos epistêmico-metodológicos (Organizador por: Maria Helena Menna Barreto Abrahão, Jorge Luiz da Cunha e Lúcia Villas Bôas, 2018); Atos de biogr@far: narrativas digitais, história, literatura $e$ artes (Organizado por Ana Chrystina Mignot, Dislane Zerbinatti Moraes, Raimundo Martins, 2018); Infâncias, juventudes, universos (auto)biográficos e narrativas (Organizado por: Maria da Conceição Passeggi, Zeila de Brito Fabri Demartini e Adelina de Oliveira Novaes, 2018); Vida, narrativa e resistência: biografização e empoderamento (Organizador por Elizeu Clementino de Souza, Paula Perin Vicentini, Celi Espasandin Lopes); Diversidades, redes de sociabilidade e histórias de vida: outros modos de narrar (Organizador por: Filomena Maria de Arruda Monteiro, Rodrigo Matos de Souza e Margaréte May Berkenbrock Rosito); Espaços formativos, trajetórias de vida e narrativas docentes (Organizador por Ecleide Cunico Furlanetto, Adair Mendes Nacarato e Terezinha Valim Oliver Gonçalves, 2018); e, Narrativas, formação e trabalho docente (Organizado por: Inês Ferreira de Souza Bragança, Bárbara Cristina Moreira Sicardi Nakayama e Douglas da Silva Tinti, 2018).

Os reflexos dessas produções realizadas por esta coleção no âmbito da pesquisa narrativa têm:

[...] contribuído a incrementar as relações entre investigadores com diferentes tradições 


\begin{abstract}
disciplinares e distintos enfoques. Igualmente, destacam nestes movimentos as reflexões epistemológicas e teóricometodológicas de investigações sobre histórias de vida e suas implicações como prática de investigação-formação (BOLÍVAR, 2018, p.14. tradução nossa).
\end{abstract}

Além do mais, as contribuições da Associação Brasileira de Pesquisa (Auto)Biográfica (BIOGRAPH) que foi criada no III CIPA em Natal (RN) no ano de 2008, vem propiciando um amplo debate e disseminação de conhecimentos no campo de pesquisas e estudos da abordagem narrativa (auto)biográfica e histórias de vida em formação, na realização de outros tantos eventos e atividades científicas que tomam como potencialidade esse campo teóricometodológico, político, e epistemológico, se tornando um meio privilegiado na formação de professores e pesquisadores que se interessam pela área, nacional e internacional.

O crescente diálogo de professores pesquisadores brasileiros com seus grupos de pesquisas em articulação com os estrangeiros tem contribuído também com a ampliação de estudos e pesquisas na corrente das narrativas (auto)biográficas e histórias de vida, que tem circulado no cenário brasileiro suas produções como é o caso das contribuições de MarieChristine Josso (Genebra/Suíça), Daniel Hugo Suárez (Argentina), António Bolívar (Espanha), Christine Delory-Momberger (França), Jorge Larrosa (Espanha), Ivor Goodson (Inglaterra), António Nóvoa (Portugal), entre outros.

A própria Josso (2020), em recente artigo publicado ${ }^{4}$, reconhece as nossas produções nessa área do conhecimento como fundamental que se transmutam em diferentes fronteiras geopolíticas perpassando pela América Latina, Europa e outras realidades evidenciando, assim, a exponencial ampliação de estudos nessa área. Segundo a autora:

\footnotetext{
4 Publicação realizada na Revista Brasileira de Pesquisa (Auto)Biográfica, que faz parte da BIOGRAPH e é outro meio de divulgação de conhecimentos científicos no campo da abordagem da pesquisa-formação narrativa (auto)biográfica e histórias de vida que tem relevantes contribuições na produção científica no Brasil, congregando pesquisadores nacionais e estrangeiros. (Ver site da revista: https://www.revistas.uneb.br/index.php/rbpab.).
}

Abordagens biográficas e

"histórias de vida"

parecem ter

funcionalidades perenes

relacionadas à

singularidade e

transformações sempre

crescentes que afetam as

fronteiras geopolíticas,

nossas fronteiras mentais

e as características dos

territórios herdados,

construídas ao longo da

vida para nos preparar

para recompor novas

funcionalidades (JOSSO,

2020, p. 43).

Portanto, como podemos perceber, os estudos e pesquisas no campo da corrente da pesquisa narrativa (auto)biográfica vem se ampliando, consideravelmente no cenário brasileiro, o que acreditamos ser uma abordagem substancial e de extrema relevância para o desenvolvimento de pesquisas e estudos que vem recuperando o protagonismo dos professores, sua formação e ajudando no processo de seu desenvolvimento profissional, para além dos esquemas clássicos que a priori vinham sendo conduzidos, e que não estavam dando conta de fazer florescer transformações plausíveis e que pudessem trazer a própria figura da pessoa professor como ator, autor e narrador de suas experiências de vida, formação e desenvolvimento profissional, e que são dimensões fundamentais que sinalizam para a produção de conhecimentos científicos da profissão.

\section{A PERTINÊNCIA DAS ESCRITAS DE SI NA FORMAÇÃO DOCENTE}

Por muito tempo a escrita foi consubstanciada pela supremacia de uma ciência clássica que passou a homogeneizar o modo de produzir conhecimento científico pautado pelos princípios de uma racionalidade técnica e forjada por um paradigma hegemônico, sem a articulação com outras formas de conhecimentos na sociedade.

Com as transformações que foram sendo descortinadas pelas pesquisas científicas ao longo do tempo, passamos a compreender que não há apenas uma forma de conhecer, muito menos de escrever, compreender, refletir e produzir conhecimentos, mas muitas outras em que 
dialogam com a cultura, os saberes de mundo e a própria pessoalidade do sujeito consigo próprio, para além da profissionalidade e de uma formação técnica-instrumental.

Diante disso, refletimos com Boaventura Santos $^{5}$ (2010), que no contexto da sociedade que temos, e que se transforma em ritmos cada vez mais acelerados, podemos empreender uma tessitura de saberes e conhecimentos que se converta em uma emancipação social, política e emancipatória, que acreditamos poder ser desenvolvida com os modos de produções de conhecimentos e suas possíveis articulações e alcances que estes possam se voltar e abarcar, dialogando entre as multiplicidades de culturas e os territórios para além do instituído e existente.

Como pesquisadores, formadores de professores e narradores, temos nos afastado de modos de escritas hegemônicas que se pautem numa visão mercadológica e vertical de produção do conhecimento científico, e por isso, acreditamos ser as escritas de si como um movimento potencial em que se tece as narrativas (auto)biográficas dos sujeitos, e que emergem conhecimentos e saberes essenciais à vida, à formação e ao desenvolvimento profissional aonde quer que estejam e com a cultura e o meio que os circundam.

Uma das razões em que a escrita narrativa se configura como essencial nos processos de formação humana e, sobretudo, no contexto da formação de professores, a qual se está refletindo neste texto, culmina com outro modo de tornar concretas as ideias e pensamentos que em muitos casos são guardamos apenas no plano da memória, os quais são acessados, cada vez mais, quando evocamos lembranças acerca de determinados acontecimentos que passamos ou que são impulsionados por outras histórias em que contamos ou que nos contam em processos de conversas e outros meios.

Ao mesmo tempo os diferentes dispositivos de tecer narrativas (auto)biográficas a que temos a nosso dispor, nos fazem perceber que registrando no plano da escrita passamos a construir uma história tanto da vida de uma pessoa, como de uma época, cultura, sociedade,

\footnotetext{
${ }^{5}$ A menção do autor nesse formato é uma escolha política que fizemos já que o mesmo tem profícuas e relevantes produções na área do conhecimento científico e que, portanto, buscamos dá visibilidade como forma de reconhecimento às suas contribuições na área da educação e outras tantas áreas do conhecimento que temos adotado.
}

tempo e etc., que vai se compondo em um documento narrativo que poderá ser acessado outros vários momentos futuros e em diferentes contextos, temporalizações e pelo próprio sujeito e outras tantas pessoas para além do narrador. Assim, entendemos que:

[...] os escritos que fazem parte a narrativa de vida, em suas múltiplas formas (biografias, autobiografias, diários, correspondências, memórias etc.), constituem, desse modo, o material privilegiado para se ter acesso à forma como os homens de uma época, de uma cultura, de um grupo social, biografam sua vida (DELORY-MOMBERGER, 2008, p.38).

As escritas de si são, portanto, um meio privilegiado de termos acesso as histórias de nossas vidas, do que fizemos ou pensamos, e que envolve uma pluralidade de histórias que nos fazem refletir e recuperar o que muitas vezes está guardado em nossa memória. Por isso, acreditamos que escrever sobre si, do que pensa e faz o sujeito se justifica pelo fato de que:

[...] Jamais atingimos diretamente o vivido. Só temos acesso a ele pela mediação das histórias. Quando queremos nos apropriar de nossa vida, nós a narramos. O único meio de termos acesso a nossa vida é percebermos - que vivemos por intermédio da escrita de uma história (ou de uma multiplicidade de histórias): de certo modo, só vivemos nossa vida escrevendo-a na linguagem das histórias (DELORY-MOMBERGER, 2008 , p. 36, grifos da autora).

Nesta perspectiva, pensar os processos pelos quais as escritas de si podem contribuir na formação de professores a que tanto desenvolvemos como acreditamos ser salutar, eis, pois, uma das possibilidades que vemos empreendendo e buscando teorizar em nossas escritas e produção do conhecimento científico. 
Trata-se, pois, de uma teorização da experiência em movimento que estamos compondo e considerando pertinente trazer como meio de tessitura de um conhecimento científico contra hegemônico e que busca ultrapassar as lógicas racionais do saber e da ciência clássica.

A escrita narrativa tem sido algo não muito desenvolvida no processo de formação de professores enquanto dispositivo metodológico na prática pedagógica dos docentes formadores e para outras finalidades, o que acreditamos ser decorrente tanto da formação a que teve o professor formador em não ter esse meio como algo de interesse em mobilizar em suas práticas, como em alguns casos, que, inclusive temos experienciado, pelas lógicas hegemônicas de produção do conhecimento científico e de modos de avaliar o aprendizado a que estamos incumbidos de realizar.

Fazer com que os sujeitos pensem por si próprios, e materializar seus pensamentos no plano da escrita pode se tornar um meio disparador para a construção de possibilidades formadoras e (auto)formadoras que desenvolve a sensibilidade, a reflexão crítica e até mesmo a tomada de consciência diante do que está pensando, fazendo ou dos percursos trilhados em sua trajetória de vida, do processo formativo, bem como da experiência e de outros movimentos capaz de transformá-lo e impulsionar a emancipação.

Tanto é assim, essa capacidade de gerar potencialidades transformadoras e de formação que a escrita narrativa permite que um brilhante trabalho desenvolvido por Josso (2010) na formação de adultos e apresentado em Experiências de vida e formação, percebeu que:

[...] o ato de escrever uma narrativa de vida, centrada na formação, constitui um espaço de reflexão e de conceitualização que pode existir por si mesmo. A constituição desse espaço efetua-se, em particular, por meio de um questionamento que desemboca no evidenciar de processos de tomar forma (processos de formação e processos de conhecimento) e numa elaboração do sentido desses processos (sob a forma de inquéritos) que transcendem, não deixando de incluir os questionamentos e as compreensões

interpretativas, trazidas por uma leitura psicológica, sociológica, antropológica da escrita da narrativa de vida ou, ainda, por uma leitura linguística (JOSSO, 2010, p. 202).

Diante disso vão constituindo-se os processos reflexivos tecidos na escrita (auto)biográfica do sujeito, em que este, passa a se ver, e enxergar outros acontecimentos e transformações que lhe são possíveis de serem percebidas, trata-se, assim, de um voltar para si frente a uma materialidade que desvela um universo de saberes, conhecimentos, aprendizagens e formações nas escritas de si.

Mediante essas experiências das escritas narrativas (auto)biográficas, temos defendido essa perspectiva como uma prática que vem sendo desenvolvida tanto pelos estudantes dos cursos de licenciaturas em que atuamos no processo de formação de professores na docência do Ensino Superior e por onde transitamos, como no que diz respeito aos professores no cotidiano das escolas no seu desenvolvimento profissional.

Primeiro porque na academia há uma dinâmica formativa da qual os sujeitos estão se apropriando de saberes teóricos, históricos, epistemológicos, metodológicos e outros como uma preparação inicial com respectivas fundamentações, as quais, os professores formadores podem contribuir para a tessitura de reflexões importantes que mediarão o desenvolvimento profissional destes futuros docentes no cotidiano das escolas, e, portanto, a prática das escritas de si, se configuram como uma perspectiva fundamental para desenvolver a reflexividade, e um si perceber nos escritos que o próprio sujeito exercita, levando a outras transformações, formação e construção de conhecimentos.

Por outro lado, no contexto do desenvolvimento profissional, os registros diários das práticas pedagógicas tecidas em narrativas que os docentes praticam, podem ser mobilizadas numa vertente de escritas narrativas (auto)biográficas, o que se revela como dispositivo potencializador de aperfeiçoamento e 
formação continuada com vistas à melhoria do aprender e ensinar cotidianamente com as crianças em sua didática.

Em uma perspectiva de articulação de sentidos e significados da atividade de escrever narrativas em composição com as leituras do narrador acerca do que escreveu, seja de futuros professores em formação docente inicial, quanto para os que estão já atuando na área, no contexto do desenvolvimento profissional, essas atividades (de produzir narrativas, ler e refletir de forma compartilhada coletivamente), produzem um efeito mobilizador de formação e aprendizado em que, vão percebendo os movimentos de escrever com que cada um tece, de acordo com o seu estilo e modo de escrita, além, de outras linguagens expressas no ato da narração, que traz afetações, sensibilidades, emoções e reflexões (auto)formadoras para quem está narrando ou ouvindo a narração. Aspectos esses que temos também desenvolvido em outros escritos (MORAIS; LIMA, 2020; MORAIS; NASCIMENTO; MAGALHÃES, 2020).

À medida que essa interação ocorre de o sujeito pensar, narrar, ler e ouvir o narrado, que pode ser ele mesmo o autor da narrativa ou outro, salientamos esse imbricamento, de forma salutar, na formação de professores, que é gerador de mudanças que o próprio sujeito se vê diante das escritas de si, como acerca da escrita do outro passando a ver pontos que se aproximam de suas experiências e dos acontecimentos que tenham passado em algum momento. Isso pode significar muito o que Bakhtin (2003, p.139) discute quando pontua que "[...] a consciência do possível narrador e o contexto axiológico do narrador organizam o ato, o pensamento e o sentido em que estão incorporados em seus valores ao mundo dos outros".

Para melhor situar a narrativa como caráter formativo, realizamos o seguinte questionamento: no processo de formação de professores, como se daria a organização desse ato em relação às escritas narrativas do outro que é lido por um sujeito que não o narrador?

Acreditamos, inclusive com base em nossa experiência como formadores de professores com o uso das escritas narrativas (auto)biográficas com os licenciandos em que estamos contribuindo no processo formativo inicial docente, que há uma pluralidade de acontecimentos, afetações, aprendizagens e formações que o narrador compreende, reflete e se apropria quando passa a narrar o que está escrito dos colegas, fruto de suas experiências. É aí que o sujeito pode se ver pela narrativa do outro, gerando também efeitos formadores e (auto)formadores, sem contar as implicações potenciais que suas próprias narrativas podem se configurar, como temos defendido nesse texto.

Escrever sobre si é também se expor, e isso leva a um estado de subjetividade e singularidade em que o sujeito se coloca diante de si como que em um espelho, pois há uma entrega para si próprio na atividade de narrar, mas que poderá ganhar outros vieses quando passa a ser compartilhada a outros a experiência narrada que fora registrada pelo sujeito em seu universo existencial narrado.

As escritas de si, no processo de formação de professores, podem apresentar sinuosidades, o que caracteriza a novidade, as descobertas e a riqueza da formação docente, por um algo em que está por vir, e que tanto o sujeito narrador pode suscitar curiosidades, expectativas e desejos para narrar, quanto os professores formadores, que se aventuram na tarefa de ler ou ouvir o estudante acerca de suas experiências singulares e irrepetíveis que já teve em sua vida. Ambos se formam e se transformam nessa atividade de narrar, ler, ouvir e refletir as histórias narrativas de vida em que um ou outro estão a compartilhar coletivamente. Em suma, é um efeito transformador.

Nesse sentido, cabe elucidar uma contribuição contundente no campo das narrativas (auto)biográficas da formação de professores, quais sejam, a de que:

[...] as escritas de si, longe de comunicar o que já se sabe, constituem-se verdadeiros processos de descoberta. Essa dimensão heurística permite a quem escreve explicitar as experiências e transformar saberes implícitos em conhecimentos (pesquisa). o narrador, ao redescobrir-se como ser aprendente reinventa-se (formação) (PASSEGGI, 2010, p. 115, grifos da autora).

O escrever sobre si, é, pois, uma das possibilidades potenciais de reflexão, transformação e emancipação quando é 
praticada no contexto da formação de professores, e desenvolvida em processos que levam em consideração a articulação entre a vida pessoal, que acaba desaguando no campo formativo e profissional.

Um exemplo dessas dimensões reflexivas que as escritas de si desvelam, pode ser percebida, quando os estudantes narram como chegaram à universidade, ou o porquê escolheram o curso que estão realizando para construir uma formação que mediará o seu desenvolvimento profissional. Outro aspecto que pode ser revelador é sua história de vida, que os acompanham de forma muito viva na memória, e que pode ser um "divisor de águas" quando pensa o passado, se vê no presente e projeta um futuro que é idealizado e desejado pelo mesmo, quando concluir essa etapa de formação inicial.

Cabe ressaltar, então, que "[...] a mais divulgada maneira de trabalhar com as narrativas no âmbito do ensino e da formação de professores tem sido a chamada história de vida ou memória pedagógica" (CUNHA, 2010, p. 205, grifos da autora).

Os dispositivos pelos quais registram essas escritas de si, como elucidado acima podem ser tecidos em um diário narrativo, como um meio privilegiado de acesso as compreensões, aprendizados e reflexões que os estudantes estão construindo na formação inicial, e que os formadores podem orientar como uma metodologia nos processos de ensino na formação universitária.

Assim, acreditamos que no memorial de formação, em que o sujeito conta a sua história de vida acessando os acontecimentos do passado (da onde veio) para si perceber no presente (aonde chegou) e projetar o futuro (aonde quer chegar) dá condições de acessar a níveis de profundidade de $\mathrm{si}$, e de uma formação emancipatória, pois amplia o leque de reflexões e tomada de consciência que o sujeito pode operar quando se vê no seu escrito e dialoga com as reflexões que os professores formadores podem tecer, e que destes, também se voltam para os licenciandos por meio de outros diálogos profícuos e pertinentes no processo formativo. Ou seja, a ideia de um memorial de formação é que neste:
[...] ocorre num processo em andamento, a escrita se dá, portanto, num espaço-tempo quase simultâneo à vivência dos fatos que devem descrever, por essa razão, os autores, que se percebem na condição de alunos, revelam suas dificuldades para dar sentido a experiências ainda em curso (CÂMARA; PASSEGGI, 2010, p. 36).

Situar as diferentes aprendizagens, as caminhadas trilhadas e os processos formativos na escrita de professores ou futuros professores em seus dispositivos de registrar narrativamente os itinerários percorridos resgatam uma multiplicidade de saberes e conhecimentos que muitas vezes extrapolam as lógicas instituídas e demarcadas de ter acesso ao que pensam e sabem os sujeitos no processo de formação.

Por outro lado, os sujeitos não apenas narram o que tem a ver com o que estão fazendo, pensando e se debruçando de seu processo formativo, mas ampliam as escritas narrativas de si, trazendo seu universo de vida, as várias reflexões e pensamentos que extrapolam os espaços institucionais e formativos, ganhando o curso dos próprios contextos em que estão imersos, fruto ainda das múltiplas relações que tecem com variadas pessoas e dos acontecimentos até mais íntimos e incomuns que na atividade de narrar são revelados.

Nos diários narrativos que temos elaborado como professores formadores na docência do Ensino Superior, nós mesmos construímos o nosso diário para nos percebermos na constituição de nossa experiência profissional no decurso de nossas caminhadas trilhadas, quanto também propomos aos estudantes dos cursos de licenciaturas que elaborem um diário para narrarem suas experiências formativas, de aprendizagem em que as escritas de si ganham curso e nos dão possibilidades de ter acesso ao universo de saberes e conhecimentos que estão construindo, paulatinamente ao longo do processo formativo.

Desse modo, acreditamos que o diário se torna um dispositivo metodológico de grande valia nos processos de formação de professores, pois traz um teor implicado de subjetividade e singularidade do narrador, em que revelam múltiplas facetas dos percursos trilhados e na própria tomada de consciência que o sujeito empreende ao escrever sobre si e trazer os muitos espaços, tempos, contextos e pessoas que 
passaram em suas vidas, que estão tecendo relações no momento e com os quais se projeta em perspectivas futuras do que reflete, idealiza ou se propõe a encarar como meta a alcançar. Nesse sentido:

[...] o diário cumpre um papel importante como elemento de expressão de vivências e emoções. Escrever sobre si mesmo traz consigo a realização dos processos a que antes referimos: racionaliza-se a vivência ao escrevê-la (o que tinha uma natureza emocional ou afetiva passa a ter, além disso, uma natureza cognitiva, tornando-se assim mais manejável), reconstrói a experiência, com isso dando a possibilidade de distanciamento e de análise $e$, no caso de deseja-lo, se facilita a possibilidade de socializar a experiência, compartilhando-a com um assessor pessoal ou com o grupo de colegas (ZABALZA, 2004, p. 18).

As escritas de si, portanto, representam uma entrega sensível, tocante e que floresce o mundo tanto interno, quanto externo dos sujeitos no que concerne ao que habitam em suas memórias e as capacidades que tem de se lembrar dos acontecimentos que já experienciou e que marcaram em sua vida, e que, por isso mesmo, ao escreverem sobre sua formação, revelam de si e dos muitos sujeitos e contextos que Ihes habitam, Ihe tocam e, portanto, o afetam.

A escrita narrativa (auto)biográfica requer tempo, dedicação e reflexão, pois o sujeito mobiliza uma atividade de pensamento que invoca a memória, as lembranças e outras dimensões capazes de transpor do plano das ideias para o plano concreto o que está pensando no ato da narração.

Portanto, não se trata de uma forma de escrita descritiva, informativa ou declarativa, mas sim, de uma narrativa, em que se conta uma história ou muitas histórias de vida do sujeito, a partir das múltiplas reflexões que se fazem presente em si, e que ganha legitimidade na atividade de narrar, suscitando o plano da subjetividade em que emerge o lado pessoal, social, político, cultural, formativo e de aprendizagens que está tecendo ou que por ventura já tenha experienciado em algum momento de sua vida.

Enfim, reiteramos a pertinência e o lugar das narrativas de si como promotoras de reflexividades (auto)biográficas transformadoras do sujeito em formação, afinal de contas "[...] Olhar, ouvir ou narrar a experiência de uma "pesquisaformação", se torna uma via indispensável no momento atual da educação e da sociedade brasileira, pelo fato de que estamos produzindo ciência e conhecimento de outras formas que extrapolam os modos canônicos de pesquisar" (BRAGANÇA; MORAIS; ALVARENGA; OLIVEIRA, 2020, p. 340).

Portanto, as escritas de si, que se refletem no dispositivo de formação inicial de professores, são parte da perspectiva de humanização do sujeito, concebidas por nós professores pesquisadores em nossas propostas de formação. Desejamos aproximar as referências teóricas e epistemológicas da narrativa na práxis pedagógica dos futuros professores, ainda incipientes na formação inicial. Como dispositivo teórico e metodológico de pesquisa-formação, a escrita de si durante o processo formativo e avaliativo, pressupõe o exercício de uma prática reflexiva, necessária à formação do profissional professor.

\section{TECENDO ALGUMAS CONSIDERAÇÕES FINAIS}

As escritas de si, revelam-se como um meio privilegiado de desenvolvimento da formação de professores que se tecem em meio a uma pluralidade de experiências de vida do sujeito, tecidas em meio a reflexividade que pratica e a tomada de consciência que emerge ao escrever as narrativas (auto)biográficas dos movimentos por onde trilha e que se revelam por meio de suas memórias.

Compreender os aspectos históricosepistemológicos da abordagem narrativa (auto)biográfica no campo da educação no Brasil, se tornou importante, até para pensarmos as lógicas pelas quais as formas de escrita do processo de formação de professores eram desenvolvidas, e quais necessidades e demandas se tornam relevantes elucidarmos, em função da sociedade que temos, do modelo de formação existente e do perfil de homem, professor e sociedade que queremos ter e formar. 
O desafio posto no processo de formação de professores no contexto de uma pedagogia narrativa é a adoção de dispositivos metodológicos na prática pedagógica pelos formadores de professores, com o uso de escritas narrativas de si, que pode ser empreendida pelo próprio formador, em diálogo com os estudantes em formação, para que criem uma cultura da escrita, e possam contribuir no seu processo formativo construindo conhecimentos e saberes necessários à profissão que os acompanharão, inclusive, no desenvolvimento profissional docente quando estiverem atuando na área.

O memorial de formação, o diário narrativo e as histórias de vida são, pois, alternativas potenciais de dispositivos metodológicos que podem, em muito, mediar as práticas formativas no espaço universitário do escrever sobre si, e tecer outras tantas reflexões, transformações e produções de conhecimentos científicos pelos licenciandos e como feedback que poderá ser reverberado nas práticas avaliativas e de compreensões dos professores formadores, acerca do entendimento das aprendizagens destes em suas trajetórias percorridas ao longo do curso em que estão realizando.

Quanto mais dispositivos metodológicos utilizarmos na formação de professores primando pelas escritas de si, tanto mais acreditamos que poderão ser profícuos seus entendimentos e reflexões da formação e da prática pedagógica, diminuindo as lacunas formativas e contribuindo para o exercício da crítica, reflexão-ação-reflexão que mediará a prática pedagógica e as mudanças que poderão desta advir em inúmeras situações problemáticas que por ventura possam surgir no cotidiano profissional.

Com as escritas de si na formação de professores, trata-se de recuperarmos os protagonismos dessa formação na própria voz dos estudantes, e assim, futuros professores, como forma de redirecionar as práticas de formação, como a possível contribuição na criação de políticas, saberes, currículos e conhecimentos importantes e pertinentes para a educação, a sociedade e à vida.

\section{REFERÊNCIAS}

ABRAHÃO, Maria Helena Menna Barreto. Intencionalidade, reflexividade, experiência e identidade em pesquisa (auto)biográfica: dimensões epistemo-empíricas em narrativas de formação In: BRAGANÇA, I. F. de S.; ABRRAHÃO,
M. H. M. B.; FERREIRA, M. S. (Orgs.). Perspectivas epistêmico-metodológicas da pesquisa (auto)biográfica. Curitiba: CRV, 2016. p. 29-50.

ABRAHÃO, Maria Helena Menna Barreto; CUNHA, Jorge Luiz da; VILLAS BÔAS, Lúcia (Orgs.). Pesquisa (auto)biográfica: diálogos epistêmicometodológicos. Curitiba: CRV, 2018. (Coleção: Pesquisa (auto)biográfica, mobilidades, incertezas e refigurações identitárias, v.1)

BRAGANÇA, Inês Ferreira de Souza. Pesquisa formação narrativa (auto)biográfica: trajetórias e tessituras teórico-metodológicas. In: ABRAHÃO, M. H; M. B.; CUNHA, J. L. da; BÔAS, L. V. (Orgs). Pesquisa narrativa (auto)biográfica: diálogos epistêmico-metodológicos. Curitiba: CRV, 2018. p. 65-81.

BRAGANÇA, Inês Ferreira de Souza; NAKAYAMA, Bárbara Cristina Moreira Sicardi; TINTI, Douglas da Silva. Narrativas, formação e trabalho docente. Curitiba: CRV, 2018. (Coleção: Pesquisa (auto)biográfica, mobilidades, incertezas e refigurações identitárias, v.7).

BRAGANÇA, Inês Ferreira de Souza; MORAIS, Joelson de Sousa; ALVARENGA, Juliana Godói de Miranda Perez; OLIVEIRA, Liliam Ricarte de. Acompanhamento em "pesquisaformação": experiências de orientação coletiva e escrita narrativa (auto)biográfica. Márgenes, Revista de educação da Universidade de Málaga (Espanha), v. 1, n. 3, p. 326-343, 2020. Disponível em: https://revistas.uma.es/index.php/mgn/article/vi ew/9484/10323. Acesso: 31 out. 2020.

DOI:10.24310/mgnmar.v1i3.9484

BAKHTIN, Mikhail. Estética da criação verbal. Tradução do russo: Paulo Bezerra. 4. ed. São Paulo: Martins Fontes, 2003.

BENJAMIN, Walter. Magia e técnica, arte e política: ensaios sobre literatura e história da cultura. Tradução: Sérgio Paulo Rouanet; prefácio Jeanne Marie Gagnebin. 8. ed São Paulo: Brasiliense, 2012.

CÂMARA, Sandra Cristinne Xavier da; PASSEGGI, Maria da Conceição. Memorial autobiográfico: uma tradição acadêmica no Brasil. In: PASSEGGI, M. da C.; VICENTINI, P. P.; ZOUZA, E. C. de (Orgs.) Pesquisa autobiográfica: narrativas de si e formação. 1ạed. Curitiba, PR: CRV, 2013. 
CUNHA, Maria Isabel da. Narrativas e formação de professores: uma abordagem emancipatória. In: SOUZA, Elizeu Clementino de; GALLEGO, Rita de Cassia (Orgs.). Espaços, tempos e gerações: perspectivas (auto)biográficas. São Paulo: Cultura Acadêmica, 2010. p. 199-214.

DELORY-MOMBERGER, Christine. Biografia e educação: figuras do indivíduo-projeto. Tradução de Maria da Conceição Passeggi, João Gomes da Silva Neto, Luís Passeggi. Natal, RN: EDUFRN; São Paulo: Paulus, 2008.

FREIRE, Paulo. Pedagogia da autonomia: saberes necessários a prática educativa. São Paulo: Paz e terra, 1996.

FURLANETTO, Ecleide Cunico; NACARATO, Adair Mendes; GONÇALVES, Terezinha Valim Oliver. Espaços formativos, trajetórias de vida e narrativas docentes. Curitiba: CRV, 2018. (Coleção: Pesquisa (auto)biográfica, mobilidades, incertezas e refigurações identitárias, v.6).

GOODSON, Ivor F. Currículo, narrativa pessoal e futuro social. tradutor: Henrique Carvalho Calado; revisão da tradução: Maria Inês PetrucciRosa e José Pereira de Queiroz. Campinas, SP: Editora da Unicamp, 2019.

JOSSO, Marie-Christine. Experiências de vida e formação. Tradução de José Cláudio, Júlia Ferreira; revisão Maria da Conceição Passeggi, Marie-Christine Josso. 2. ed. rev. e ampl. Natal, RN: EDUFRN; São Paulo: Paulus, 2010.

JOSSO, Marie-Christine. Histórias de vida e formação: suas funcionalidades em pesquisa, formação e práticas sociais. Revista brasileira de pesquisa (auto)biográfica, Salvador, v. 5, n. 13, p. 40-56, jan./abr., 2020. Disponível em: https://www.revistas.uneb.br/index.php/rbpab/a rticle/view/8423/5390. Acesso: 31 out. 2020.

MIGNOT, Ana Chrystina; MORAES, Dislane Zerbinatti; MARTINS, Raimundo (Orgs.). Atos de biogr@far: narrativas digitais, história, literatura e artes. Curitiba: CRV, 2018. (Coleção: Pesquisa (auto)biográfica, mobilidades, incertezas e refigurações identitárias, v.2).

MONTEIRO, Filomena Maria de Arruda; SOUZA, Rodrigo Matos de; ROSITO, Margaréte May Berkenbrock (Orgs.). Diversidades, redes de sociabilidade e histórias de vida: outros modos de narrar. Curitiba: CRV, 2018. (Coleção: Pesquisa (auto)biográfica, mobilidades, incertezas e refigurações identitárias, v.5).

MORAIS, Joelson de Sousa; LIMA, Maria Divina Ferreira. A escrita narrativa no processo de (auto)formação do pesquisador educacional. Revista Iniciação \& Formação Docente, v. 7, n. 2, p. 294-309, 2020. Disponível em: http://seer.uftm.edu.br/revistaeletronica/index.p $\mathrm{hp} /$ revistagepadle/article/view/4463/pdf.

Acesso: 30 out. 2020.

MORAIS, Joelson de Sousa; NASCIMENTO, FrancLane Sousa Carvalho do; MAGALHÃES, Nadja Regina Sousa. Evocações narrativas de gestores escolares acerca das políticas de saberes e fazeres da gestão. Revista de educação, ciência e cultura (RECC), Canoas, v. 25, n. 2, p. 221-237, jul., 2020. Disponível em: https://revistas.unilasalle.edu.br/index.php/Educ acao/article/view/6430/pdf. Acesso: 31 out. 2020.

DOI:10.18316/recc.v25i2.6430

NÓVOA, Antônio (Org). Vida de professores. Lisboa: Dom Quixote, 1992.

NÓVOA, António; FINGER, Matthias. 0 método (auto)biográfico e a formação. Natal, RN: EDUFRN; São Paulo: Paulus, 2010.

PASSEGGI, Maria da Conceição; SOUZA, Elizeu Clementino de. O movimento (auto)biográfico no Brasil: esboço de suas configurações no campo educacional. Investigación qualitativa, v. 2, n. 1 p. 6-26. 2017. Disponível em: https://ojs.revistainvestigacioncualitativa.com/in dex.php/ric/article/view/56/36. Acesso em: 29 ago. 2020.

PASSEGGI, Maria da Conceição. Narrar é humano! Autobiografar é um processo civilizatório. In: PASSEGGI, M. da C.; SILVA, V. B. da. Invenções de vidas, compreensão de itinerários e alternativas de formação. São Paulo: Cultura Acadêmica, 2010.

PASSEGGI, Maria da Conceição; DEMARTINI, Zeila de Brito Fabri; NOVAES, Adelina de Oliveira (Orgs.) Infâncias, juventudes, universos (auto)biográficos e narrativas. Curitiba: CRV, 2018. (Coleção: Pesquisa (auto)biográfica, 
mobilidades, incertezas e refigurações identitárias, v.3).

SANTOS, Boaventura de Sousa. A gramática do tempo: para uma nova cultura política. 3. ed. São Paulo: Cortez, 2010.

SOUZA, Elizeu Clementino de; VICENTINI, Paula Perin; LOPES, Celi Espasandin (Orgs.). Vida, narrativa e resistência: biografização e empoderamento. Curitiba: CRV, 2018. (Coleção: Pesquisa (auto)biográfica, mobilidades, incertezas e refigurações identitárias, v.4).

ZABALZA, Miguel A. Diários de aula: um instrumento de pesquisa e desenvolvimento profissional. Tradução Ernani Rosa. Porto Alegre: Artmed, 2004. 